\section{International Scientific Journal Theoretical \& Applied Science}

\author{
p-ISSN: 2308-4944 (print) e-ISSN: 2409-0085 (online) \\ Year: $2015 \quad$ Issue: $07 \quad$ Volume: 27
}

Published: $30.07 .2015 \quad \underline{\text { http://T-Science.org }}$
Marfua Azizovna Khamidova

professor, doctor of art criticism, professor of State institute of arts and culture of Uzbekistan, academician of the Academy of Art of the Republic of Kazakhstan mirzokozimxon@gmail.com

SECTION 16. Music. Cinema art. Theatre.

\title{
FROM THE HISTORY OF VOKAL AND PERFORMING ARTS IN FRANCE XVII-XIX CENTURIES
}

\begin{abstract}
The present article deals the history of vocal and performing arts in France during the 17-19 centuries. It says about the origins of the French National Opera, about the first opera works of French composers, which are characterized by the unity of search words, melodies and actions of the operas, vocal pedagogy and practice of different eras (European classicism and romanticism), and their impact on the establishment and development of French academic school of singing, won with a time of world-wide significance.

Key words: Vocal Art, academic singing, french opera, opera essay, vocals, singing voice, aria, recitation, phonation, quality of a voice, registers, range, cantabile, bel canto, choral mechanism, vocal technique, the technique of singing, expression.

Language: Russian

Citation: Khamidova MA (2015) FROM THE HISTORY OF VOKAL AND PERFORMING ARTS IN FRANCE XVII-XIX CENTURIES. ISJ Theoretical \& Applied Science 07 (27): 138-142.

Soi: http://s-o-i.org/1.1/TAS-07-27-24 Doi: crossef http://dx.doi.org/10.15863/TAS.2015.07.27.24

\section{ИЗ ИСТОРИИ ВОКАЛЬНО-ИСПОЛНИТЕЛЬСКОГО ИСКУССТВА ФРАНЦИИ ХVII - ХІХ ВВ.}

Аннотация: В настоящей статье прослеживается история вокально-исполнительского искусства Франциии на протяжении XVII - XIX вв. Здесь говорится об истоках франиузской национальной оперы, о первых оперных сочинениях франиузских композиторов, для которых характерен поиск единства слова, мелодики и действия, об операх, вокальной практике и педагогике разных эпох (эпохи европейского классицизма и романтизма) и их влиянии на становление и развитие французской академической школь пения, завоевавшей со временем мировое значение.

Ключевые слова: : вокальное искусство, академическое пение, французская опера, оперное сочинение, вокальные партии, певческий голос, ария, декламация, речитатив, голосообразование, тембр голоса, регистры, диапазон, кантилена (cantabile), красивое пение (bel canto), певческий механизм, вокальная техника, методика пения, экспрессия.
\end{abstract}

Формирование во Франции вокального искусства теснейшим образом связано с ренессансными устремлениями в поэзии и музыке, которые выразились в поиске органического единства мелодики, слова и драматического действия. Именно такого рода задачу преследовали Музыкальные общества и Академии («Академия поэзии и музыки» А.Баифа в Париже, 1570), объединившие в своих рядах лучшие творческие и интеллектуальные силы, способные реализовать культурные приоритеты своего времени.

Первая французская опера «Помона» Робера Камбера (либретто Перрена), поставленная в 1671 году в Королевской академии музыки, а также последующие оперные сочинения французских композиторов XVII века, имеют свою историю и своих предшественников.

Это одноголосные народные песни и шансон, гугенотские псалмы, светская музыка гомофонно-гармонического склада; ярмарочные представления, пьесы и интермедии, которые разыгрывались между актами лирической трагедия; народная комическая опера водевильного типа, построенная на речевых интонациях; наконец, это популярные, особенно в конце XVI - начале XVII вв., придворные балетные спектакли с пением [12, с. 49].

В середине XVII века - в эпоху расцвета европейского классицизма - французская опера 
обратилась к античному театру с его героями, сюжетами, строгостью и соразмерностью формы, что потребовало соответствующего музыкального языка и исполнительских навыков, основанных на выразительном слове, умении изображать драматические страсти. И если итальянская опера опиралась на певца-виртуоза, то французская - на поющего актера и балетный дивертисмент.

Эта тенденция давала о себе знать и в последующие годы, выражая драму событий и характеров посредством музыки, пения и хореографии, в строгом следовании закону трех единств: времени, места и действия, что предполагало также ограниченность числа участников, отсутствие побочных линий, крупных хоров, ансамблей, развернутых оркестровых разделов.

В операх Жана Баттиста Люлли (1632-1687), таких как «Кадм и Гермиона», «Альцеста», «Тезей», «Прозерпина», а также «Ацис и Галатея», «Армида», согласно господствовавшему тогда этикету абсолютизировался целый свод правил. Это прологи в честь короля, последовательное чередование арий, хоров, танцев, инструментальной музыки. Это речитативы в традициях «александрийского стиха», массовые хоровые и балетные номера, костюмы в стиле дворцовой моды, пышные декорации, зрелищность, изысканные манеры, символика красок, пластики [11, с. 73].

Названные самим композитором «лирическими трагедиями» («tragedies lyriques»), изобилующие разговорными эпизодами в строго определенных ритмах и размерах (в духе драматургии Пьера Корнеля и Жана Расина), они демонстрировали больше искусство декламации, риторики, высокопарной игры, а не красоту пения и виртуозного владения звуком.

Вокальные партии опер Жана Баттиста Люлли строятся преимущественно на куплетнострофической форме, основанной на силлабическом принципе [9, с. 187]. Встречаются также относительно развернутые арии, сценымонологи с большими интервальными скачками, переходами из регистра в регистр, выражающие посредством динамических контрастов, подчеркнутых жестов, мимики, неожиданной смены размеров сильные, противоречивые чувства

В оперных сочинениях Андреа Кампра и Андреа Детуша число балетных номеров растет, исполнители предпочитают форсированное звучание голоса и аффектированную игру $[13$, с. 47].

В лирических трагедиях и операх-балетах «Ипполит и Арисия», «Кастор и Поллукс», «Дарданус», «Галантная Индия» французского композитора - классициста Жана Филиппа Рамо (1683-1764), где также соединились пение, танец, актерская игра, музыка и театральность, наряду с речитативом, звучат мелодичные арии широкого диапазона, требующие профессионального исполнения. Однако увлеченная декламацией Франция не располагала к тому времени певцами соответствующего уровня.

К середине XVIII века «tragedie lyrique», подчиненная ряду условностей и выражающая придворно-аристократическую эстетику, уступает позиции комической опере, выросшей из народных представлений. Началом тому послужила опера-буффа «Служанка-госпожа» Перголези в постановке итальянцев, показанная в 1752 году парижской публике и вызвавшая восторг французских просветителей. За демократизацию жанра выступил и Жан Жак Руссо (1712-1778) - автор оперы-буффа «Деревенский колдун» на сюжет и музыку в народном духе.

Комическую оперу писали французские композиторы XVIII века Дуни («Два охотника»), Филидор («Дровосек», «Кузнец»), Монсиньи («Дезертир»), Гретри («Ричард Львиное Сердце»). Увлеченные больше простонародными сюжетами и характерами, острым словом и народным юмором, они меньше всего думали об оперной форме и профессиональном пении, что сказывалось и в качестве постановок.

Значительно дальше своих предшественников и современников продвинулся, в плане поиска музыкальновокальных средств выразительности, Христофор Глюк (1714-1787). Уже в первых своих операх, таких как «Орфей и Эвридика» (1762, либретто Р. Кальцабиджи), «Альцеста» (1767, либретто Р. Кальцабиджи, по трагедии Еврипида), «Парис и Елена» (1770, либретто Р.Кальцабиджи), написанных на итальянском языке, автор ставит цель создания масштабного музыкальносценического полотна с непрерывным развитием действия, рельефно подчеркнутым выражением чувств и переживаний.

В последующих трех своих операх «Ифигения в Авлиде» (1774, либретто Л. дю Руле, по трагедии Ж. Расина), «Армида» (1777, либретто Ф. Кино, по поэме Т. Тассо «Освобожденный Иерусалим»), «Ифигения в Тавриде» (1779, либретто Ф. Гийара, по трагедии Эврипида) [7, с. 397], прозвучавших на французском языке, Христофор Глюк стремится к единству слова и пения, музыки и драмы. Он создает новые формы речитатива, соответствующие эмоционально насыщенной речи, использует хоровые, оркестровые и балетные эпизоды. Его герои «не столько живые люди, сколько носители больших чувств. Это сложные образы, созданные поэтом и 
композитором» [4, с. 43], которые благодаря возвышенным страстям и благородству поступков выходят за рамки лирической образности, достигая высокого трагедийного наполнения.

В работе с певцами Христофор Глюк ломает сложившиеся каноны аффектированной игры, жеста и мимики, добиваясь простоты, естественности, правдивости исполнения. Однако в его сочинениях, где музыка является «служанкой поэзии», остается очевидным приоритет слова, декламации.

В конце XVIII века, в годы французской революции, появляются оперы - апофеозы, оперы спасения, музыкальное содержание которых представляет собой чередование оркестровых и куплетных форм. Сочетая патетику, мелодраму и бытовую комедию, они в свою очередь демонстрировали приоритет актерско-драматического начала, тогда как пению отводилась всего лишь вспомогательная роль.

В сложившейся в XVII - XVIII вв. во Франции вокальной ситуации, которая желала тогда много лучшего, пытаются разобраться педагоги-практики и теоретики. Вопросам развития певческого искусства посвящены опубликованные в 1668 году в Париже «Комментарии к искусству пения» М.Басили (1625-1692). Главным считает автор наличие тонкого слуха - залога успеха на исполнительском поприще, «что ведет к пониманию природы пения» [1, с. 166].

Автор рекомендует слушать хороших певцов, постоянно работать над собой, исполнять упражнения медленно и громко, учиться четкому произношению, развивать фальцет, который помогает расширить диапазон голоса.

Серьёзной попыткой осветить, проанализировать существующие проблемы и положительный опыт в состоянии вокальной педагогики Франции, является книга Берара (1710-1772) «Искусство пения» («L' art du chant»), опубликованная в 1755 году в Париже. Разрабатывая теоретические аспекты вокального исполнительства, особое внимание автор уделяет физиологии пения, показывает зависимость видов голоса от особенностей голосовых связок, которые имеют различную толщину, длину и напряжение. Известный педагог и теоретик, он обосновывает преимущества грудобрюшного дыхания, даёт конкретные рекомендации по развитию дыхательной техники. Певца, умеющего воспроизводить «звуки сильные, величественные и заглушенные, или звуки легкие, нежные и манерные и таким образом выражать все оттенки страсти», Берар сравнивает «с художником, который отлично владеет колоритом и экспрессией» [5, с. 55].
Выработке единого метода вокального воспитания на основе итальянского bel canto посвящена «Методика обучения пению в консерватории» («Methode de chant du Conservatoire de musique»), созданная в 1803 году педагогами Парижской консерватории Мингоцци и Гара, при участии композитора Керубини. Посвященная различным сторонам исполнительского творчества, она даёт ценные сведения о механизме голосообразования и дыхания, от которого зависят качество и емкость звука, умение хорошо фразировать, сохранять силу и тембр голоса [5, с. 56].

Называя регистрами «известное число звуков голоса, характер которых отличается от другого ряда звуков, образующих другой регистр» [там же], авторы делят все мужские, а также средние и низкие женские голоса на два (грудной и головной), а высокие сопрано - на три (грудной, медиум и головной) регистра. Они предлагают упражнения по выравниванию диапазона посредством исполнения диатонической и хроматической гамм (медленно, частями, legato и staccato), по сольфеджированию, вокализации (главным образом на «А» и «Е») и атаке звука, которая производится без подготовки, точно и свободно. Здесь же даны указания относительно исполнения portamento. Основным условием данной школы остается опора на bel canto и пение cantabile, требующие многолетнего, упорного труда и профессионального обучения.

В числе учеников Пьера Жана Гара (17611825) - знаменитые тенора Луи Нурри (17801831), Луи Антуан Поншар (1787-1866). Александр Хорон (1772-1839) воспитал выдающегося французского оперного певца Жильбера Луи Дюпре (1806-1896), совершившего переворот в профессиональной вокальной практике и педагогике.

Как видно, французское оперноакадемическое пение, опираясь на итальянское bel canto, не порывало связи с местной исполнительской традицией, где отдано предпочтение драматически насыщенному, экспрессивно выраженному слову. Подтверждением тому являются и высказывания педагогов-вокалистов о колорите, сочетании страсти, лирики, слова и действия, и пропаганда ими свободной атаки звука и грудобрюшного дыхания. Углубив и расширив в свою очередь познания в области физиологии певческого механизма, охарактеризовав физическое состояние тела при дыхании, обосновав существование третьего регистра у высоких женских голосов и, наконец, дав конкретные рекомендации по развитию вокальной техники, они внесли заметный вклад в теорию и практику вокального искусства. Самое главное, пришли к 
пониманию того, что для развития национальной школы необходимо соединить базовые ценности итальянской классической школы с особенностями национальной поэтической, музыкальной и исполнительской культуры.

Эта проблема особенно обострилась в связи с операми на французском языке, требующем соответствующей вокально-речевой организации, которая сочетала бы свойственную французам любовь к слову, доподлинному воспроизведению всех оттенков поэтического высказывания с технологией вокального мастерства, соблюдением всех его незыблемых правил, исходящих из закономерностей звукообразования. Как произносить букву в конце слова, как произносить открытые, закрытые гласные, соблюдая правила нейтрализации, прикрытия? Как быть с произношением гортанных, носовых звуков и т.д.? Эти и другие вопросы нашли в дальнейшем свое теоретическое осмысление и практическое разрешение.

В 1835 году в Париже появляется исследование Генриха-Фердинанда Манштейна (1806-1872) «Systeme de la grande methode de chant de Bernacchi de Bologne» («Великая Болонская школа Бернакки»), где автор, следуя традиции Болонской школы, настаивает на дыхании без толчков и расширения живота. По его мнению, «живот должен быть втянут, а грудь должна подниматься и опускаться незаметно, чтобы набранного воздуха хватало на возможно продолжительное время» [6, с. 59].

Основными критериями певческого мастерства Манштейн считает образцовое звукоизвлечение, совершенное portamento, глубину чувств, изысканный вкус, благородное, ясное произношение. Экспрессию он называет «душой» пения, которое становится искусством тогда, когда и исполнение и экспрессия одинаково хороши. Профессиональное образование, артистические качества, шлифующие богатый природный талант, играют, по твердому убеждению маэстро, основополагающую роль.

В области вокальной педагогики успешно работает Алексис Гароде (1779-1852). Автор «Methode de chant» («Методики пения», изданной в 1809 году в Париже), он впервые в научный обиход и вокально-педагогическую практику ввел понятие «смешанный регистр» для высоких мужских голосов, который более органично связывает грудной и головной регистры.

Жильбер-Луи Дюпре в своем сочинении «L arte del canto» («Искусство пения», Париж, 1846) изучает механизм голосоведения, принципы образования грудных прикрытых звуков (vois sombree), обосновывает необходимость формирования смешанного регистра и прикрытия (округления, затемнения) верхней части диапазона. Соединение регистров и ровность голоса на всем диапазоне как важнейшие требования классической школы достигаются, по мнению педагога, с величайшими предосторожностями [13, с. 54].

В развитии вокального искусства Франции XIX века огромную роль сыграл яркий представитель классической школы пения Мануэль Гарсиа, давший миру двух блистательных певиц в лице своих дочерей Марии Малибран и Паулины Виардо и выдающегося теоретика и педагога-вокалиста Мануэля Гарсиа - сына.

Гарсиа - сын (1805 - 1908) пошел дальше своего отца, изучив с помощью изобретенного им ларингоскопа голосовой аппарат и изложив свои наблюдения в книге «Traite complet de l'art du chant» («Полный трактат об искусстве пения»), изданной в Париже в 1847 и 1856 годах. Рассматривая певческий механизм как результат взаимодействия различных звукообразующих факторов, он научно обосновал понятия «регистры», «тембры», «человеческий голос», подсчитал расход воздуха в различных высотах, показал зависимость диапазона, качества и окраски голоса от физического строения гортани и глотки.

Методические принципы Гарсиа-сына во многом обусловили характер исполнительского стиля своего времени, открыв новые возможности человеческого голоса, в частности - его способность меняться, приобретать те или иные эмоциональные и драматические окраски, нюансы, полноту и направленность звучания. Поскольку, как полагает автор, «в человеке все связано, и всякое душевное движение отзывается на всем его поведении», то певческое дарование без чувственного наполнения, без экспрессии меркнет, теряет эмоциональную яркость и содержательную глубину [6, с. 105].

«Единством» Гарсиа-сын называет строгий отбор художественных приемов, полную согласованность между различными частями целого. Он также говорит о важности соответствия внешнего действия тону голоса, жесту и интонации, а тембра - душевному движению, которое продиктовано произведением [6, с. 60-61].

Итак, выработав такие понятия, как смешанный регистр и оперно-прикрытое голосообразование (округление и затемнение), вокальная педагогика Франции (в том числе в лице Гарсиа-сына, его предшественников и последователей), изменила звучание высоких нот, нашла научное обоснование сущности регистров, тембров человеческого голоса, объяснила функции певческого аппарата, подчеркнула важность органического единства содержания и 
средств выражения. Придерживаясь основных установок академического пения, таких как ровность и сглаженность регистров, округлость и нейтральность гласных, певучесть и беглость, опора на дыхание и экспрессия, она соединила кантилену с декламационным стилем, пылкие фразы и гибкий речитатив с драматической экспрессией и сгущенным психологизмом, что соответствовало содержанию и стилистике национальной оперы в развитии.

На рубеже XIX - XX веков вокальная практика Франции, сделавшая за минувшие столетия успешный рывок от драматической декламации к гибкой и выразительной вокальной мелодике, в связи с новым оперным репертуаром, где нашли место интервальные скачки и неожиданные паузы, хроматические ходы и смещения темпоритмов, обнаруживает новые черты как приметы времени. Однако сохраняя особенности национального языка (стилистические и фонетические) и национального характера, динамические и тембровые краски, свободно льющийся и однородный певческий звук, широкое использование всех участков диапазона, а также смешанное, оперно-прикрытое голосообразование, французский опыт заявляет о себе как о художественном явлении мирового уровня.

Певцы разных эпох - представители французской академической школы пения, такие как Луи Нурри, Луи Антуан Поншар, Жильбер Луи Дюпре, Мадлен София Арнольд, Жаннетта Фаллис-Андрие, Полина Виардо-Гарсиа, Мария Фелисита Малибран, Дезире Арто, Мари ГаллиМарье, Рубен Мадо - яркое тому свидетельство.

\section{References:}

1. Bagadurov VA (1956) Ocherki po istorii vokalnoy pedagogiki. - 2 izd. pererab. i dop. Moscow: Muzgiz, 268 p.

2. Garsiya M (1956) Shkola peniya. - Moscow, $128 \mathrm{p}$.

3. Livanova $\mathrm{T}$ (1983) Istoriya zapadno yevropeyskoy muziki do 1789 goda, t.1. Moscow, 696 p.

4. Lvov ML (1964) Iz istorii vokalnogo iskusstva. - Moscow: Muzika, 228 p.

5. Mazurin KM (1902) Metodologiya peniya. T.1. - Moscow, 914 p.

6. Nazarenko IK (1968) Iskusstvo peniya. - M.-L.: Muzgiz, 324 p.

7. Rasin J (1977) Tragedii. - Novosibirsk: Nauka, $436 \mathrm{p}$.
8. Rozenshild K (1978) Istoriya zarubejnoy muziki. - Moscow: Muzika, 544 p.

9. Rolan R (1938) Muzikanti proshlix let. Moscow: Muzgiz, 408 p.

10. Rolan R (1931) Opera v XVII veke. - Moscow, $132 \mathrm{p}$.

11. Khamidova MA (2013) Etiket i etiketnaya situatsiaya na stsene// Zbiór raportów naukowych. "Teoria i praktyka-znachenie badań naukowych". - Lublin, 2013. - p. 71-75.

12. Kxamidova MA, et al. (2009) Xonandalik san'ati tarixi. - Toshkent: San'at, 248 p.

13. Yaroslavtseva LK (1981) Zarubejniye vokalniye shkoli. - Moscow: GMPI im Gnesinix, 92 p. 